\title{
Evaluation of Fuel Cell Vehicle Regarding Hybridization Degree and Its Impact on Range, Weight and Energy Consumption
}

\author{
Marina Roche and Natalia Artal \\ Applus IDIADA group, Santa Oliva (Tarragona), E-43710, Spain
}

\begin{abstract}
PUMA Mind is a co-funded project aimed at enhancing the understanding of the behavior of fuel cell systems in vehicles taking advantage of the new freedoms in design that electric powertrains provide. Within this project, IDIADA focused on the integration of fuel cell systems in the automotive sector and the resulting fuel cell power demand profiles were used as base line to develop the fuel cell technology within the scope of the project. This paper presents a further study on the PUMA Mind vehicles with the simulation software for Simulink environment vemSim developed at IDIADA. The paper deals with the sizing of a pure fuel cell vehicle, a hybrid fuel cell vehicle and a plug-in hybrid fuel cell vehicle. For each case, a dynamic vehicle model and an energy management algorithm were implemented in vemSim in order to calculate the required energy storage and optimize the powertrain efficiency and range in a variety of real driving conditions. Finally, simulations results were used to evaluate the impact of the hybridization degree on vehicle weight, components size, hydrogen and electric consumption and variability of the fuel cell and battery load. Those results unveil that all typologies of hybridization mentioned in the following paragraphs reach the target of range and obtain good performances according to different mission profiles.
\end{abstract}

Key words: Fuel cell, hybrid, plug-in, simulation, range.

\section{Introduction}

Contamination and its impact on health and climatic change are some of the main priorities of society today. Increasingly more people are convinced that vehicles with ICE (internal combustion engines) need to be replaced by more efficient powertrain technologies with the main objective of achieving "zero emissions" or at least greener vehicles.

The $19^{\text {th }}$ century was the century of steam engine, the $20^{\text {th }}$ was the century of the ICE, but in the 1990's, hybrid and electricpowertrain architectures became serious alternatives, although the concept was not entirely new. A hybrid vehicle uses two or more different power sources for propulsion. The most

Corresponding author: Natalia Artal, mechanical engineer, research fields: automotive, electric \& hybrid vehicles, fuel cell technologies and new propulsion sources. E-mail: Natalia.Artal@idiada.com.

This paper was originally presented at EEVC Congress 2015. widespread configuration is the hybrid electric vehicle which uses an ICE as primary power source and batteries as accumulators, but hydraulic and pneumatic hybrids are also being sold as reasonable alternatives.

However, in order to reduce emissions and the dependency on fossil fuels, a transition in alternative energy sources is expected in the next few years, thus, a mix of biofuels, hydrogen and electricity is expected to be found in the future. The freedom in design that electric drivesprovide permits developing new powertrain architectures with other propulsion systems such as FC (fuel cell) [1]. The $21^{\text {st }}$ century is supposed to be the century of FC as a result of the large amount of researches performed in the hydrogen technology in the last years. Although hydrogen is not a renewable resource, it is an abundant element and can be obtained by means of renewable sources. 

Impact on Range, Weight and Energy Consumption

\section{Objective}

The main goal of the study within the PUMA Mind project [2] was to compare three FC vehicle configurations with different hybridization levels in terms of FC load profiles, weight and performance by maintaining the same range target of $500 \mathrm{~km}$ for NEDC (new European driving cycle) and good performances in energy saving for 5 mission profiles. The results used to compare each vehicle design are:

- weight and capacity of accumulators;

- FC and battery load profiles;

- range and full electric range;

- $\mathrm{H}_{2}$ consumption;

- electric consumption;

- average FC efficiency during operation.

The energy management algorithms were optimized in order to operate close to the FC maximum efficiency point and at reasonable battery SOC (state of charge) in a variety of driving scenarios represented by the mission profiles. The study concluded with three FC load profiles to be used for automotive FC system emulation on a single stack. In the following paragraphs, the conditions in which the simulations were set are discussed.

\subsection{Vehicle Architectures}

The target concept vehicles were set in the PUMA Mind project [2] premises and consisted of a pure FC vehicle, a hybrid FC vehicle and a plug-in hybrid FC vehicle with FC powers of $100 \mathrm{~kW}, 30 \mathrm{~kW}$ and $8 \mathrm{~kW}$, respectively. The architecture selected was front wheel drive with one motor and differential. The main differences in their propulsion systems are evidenced in Table 1.

\subsubsection{Pure FC Configuration}

In this architecture the hydrogen is the only energy source for propulsion and there is just a tiny accumulator to satisfy auxiliaries' consumption.

Fig. 1 shows the vehicle architecture implemented in Simulink environment with the simulation software vemSim. In this configuration the FC must absorb the instantaneous cycle power profile and regenerative braking is not possible. For this configuration the DC-DC is not required as long as the inverter can absorb the voltage variations of the FC, and therefore, the energy loss in the DC-DC is avoided.

\subsubsection{Hybrid FC Configuration}

In this configuration there is a small traction battery that allows the FC to follow a softened power profile and the motors to perform regenerative braking. However, a DC-DC converter device is required to connect FC and traction battery. Fig. 2 shows a detail of the model implemented in vemSim.

\subsubsection{Plug-in Hybrid FC Configuration}

This configuration is similar to a hybrid FC vehicle with the main difference that the battery can be externally charged to also provide a full electric range (Fig. 3).

In this configuration the $\mathrm{FC}$ acts as a range extender and the battery is the main energy accumulator allowing

Table 1 Vehicles' main traction components.
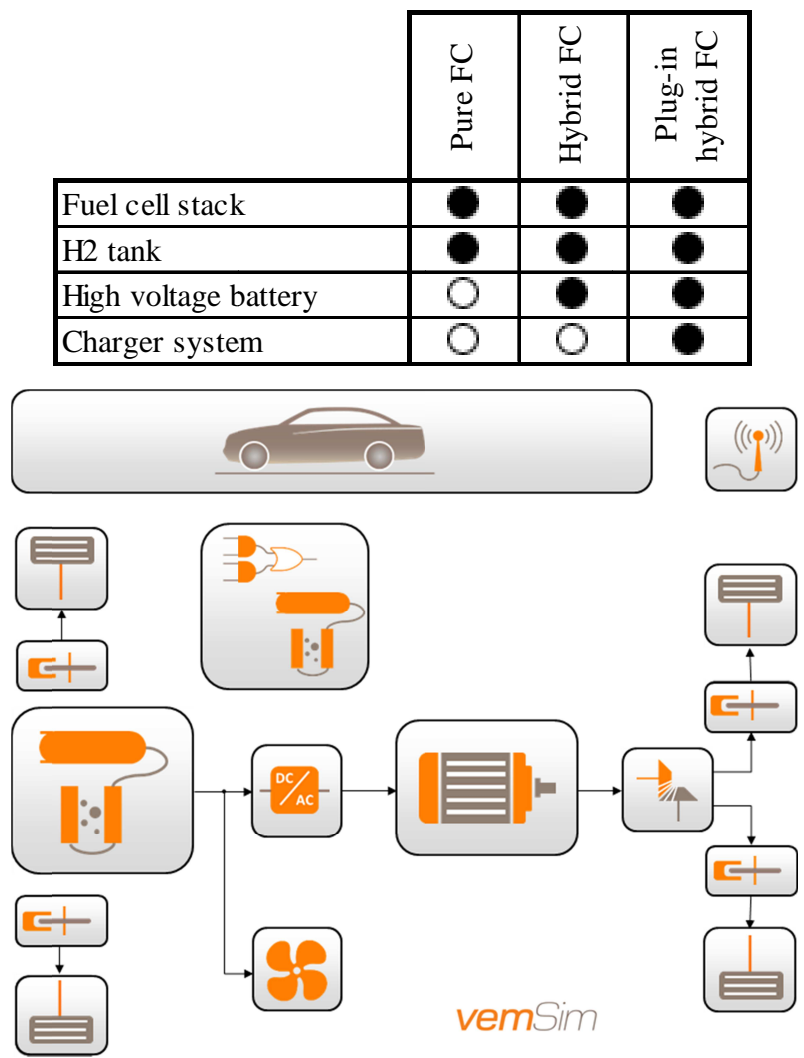

Fig. 1 VemSim model for a pure FC vehicle. 

Impact on Range, Weight and Energy Consumption

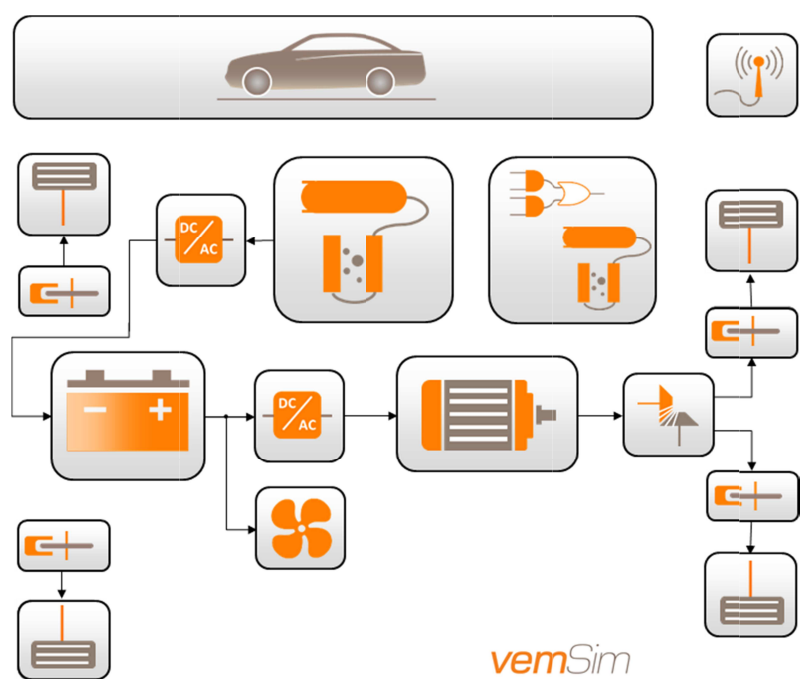

Fig. 2 VemSim detail for a hybrid FC vehicle.

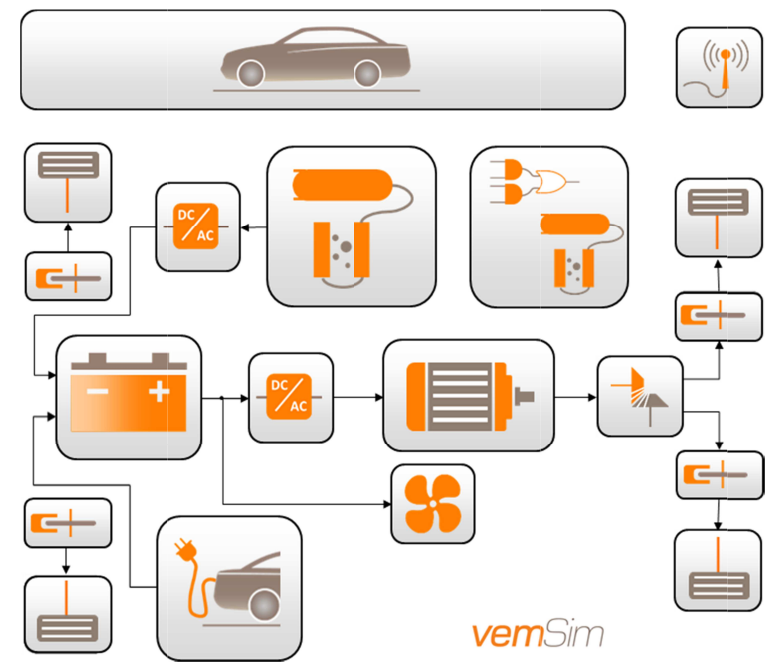

Fig. 3 VemSim detail for a plug-in hybrid FC vehicle.

regenerative braking. As in the hybrid $\mathrm{FC}$ vehicle, a DC-DC converter connects the FC and the traction battery.

\subsection{Vehicle Characteristics}

In order to simulate the impact of the integration of a FC system on a real traction system [3], standard market's vehicle characteristics were used for simulation as shown in Table 2.

The basis vehicle weight was calculated excluding FC system, hydrogen tank and traction battery weights. To obtain this weight it was considered that a conventional C-Segment car weighs around $1,200 \mathrm{~kg}$ to $1,300 \mathrm{~kg}$. For a FC vehicle the ICE system weight
Table 2 Vehicle characteristics used for simulation.

\begin{tabular}{|l|r|}
\hline \multicolumn{2}{|c|}{ Vehicle characteristics } \\
\hline Vehicle Class & C-Segment \\
\hline Vehicle basis weight (kg) & 1100 \\
\hline \multicolumn{2}{|c|}{ Vehicle resistance to movement } \\
\hline Aerodynamic drag coefficient (Cd) & 0.3 \\
\hline Frontal area (A) (m2) & 1.91 \\
\hline Tire drag coefficient (t/t) & 0.0085 \\
\hline \multicolumn{2}{|c|}{ Powertrain parameters } \\
\hline Architecture & 1 Motor, frontal \\
\hline Tire & $205 / 55 \mathrm{R} 16$ \\
\hline Motor average efficiency & $80 \%$ \\
\hline Motor power (kW) & 70 \\
\hline Reducer efficiency & $97 \%$ \\
\hline Differential efficiency & $98 \%$ \\
\hline Equivalent inertia of rotating parts & $5 \%$ of total weight \\
\hline Auxiliaries' consumption (W) & 400 \\
\hline
\end{tabular}

(engine + fuel tank + auxiliaries) is removed and the gearbox is substituted with a fixed gear, which is lighter. However, motor, inverter and EV (electric vehicle) auxiliaries are included, and their weight can be approximately 100-150 kg. Therefore, this weight of $1,100 \mathrm{~kg}$ was set as vehicle basis for a C-Segment.

Regarding resistance to movement parameters, the aim was to be in accordance with the coefficients and size of a standard C-Segment vehicle and therefore, a market study was performed to obtain these values. The tire drag coefficient corresponds to a 205/55R16 with efficiency label C (as per regulation 1222/2009 C1) [4].

The powertrain parameters present a relevant impact on the vehicle performance. Motors of electric vehicles on the market were evaluated to size the motor power, with the result of $70 \mathrm{~kW}$ as a representative value and an estimated average efficiency of $80 \%$. The permanent $12 \mathrm{~V}$ consumption for vehicle electronics was considered as $400 \mathrm{~W}$ (without FC specific cooling devices).

In short, the parameters previously set aim to meet a real C-Segment vehicle design, configuration and performance.

\subsubsection{Regenerative Braking}

Regarding regenerative braking, simulations showed 
that for the vehicle characteristics and the cycles to be followed, under a good brake control, it is possible to perform all the decelerations NEDC cycle with regenerative brake only. This premise was used to simulate the different cycles on the hybrid FC and plug-in hybrid FC vehicle, and thus, it is an assumption that no hydraulic brake is used and that the brake energy is recovered taking into account the powertrain components' efficiency.

\subsubsection{Propulsion System Characteristics}

The FC power for each vehicle was a requirement from the PUMA Mind project [2] scope, while the battery or the hybrid cases was set to satisfy the energy and power demand of the drive cycles. The power stablished in the PUMA Mind project [2] for the FCs of the pure FC, hybrid FC and plug-in hybrid FC configurations is $100 \mathrm{~kW}, 30 \mathrm{~kW}$ and $8 \mathrm{~kW}$, respectively. The power characteristics of the three simulated vehicles are summarized in Table 3 . It can be observed that the plug-in hybrid FC battery provides more power than the minimum required because its size is suited to high energy storage.

The main characteristics of the accumulation [5] and traction systems used for simulation are shown in Table 4. As mentioned above, the pure FC vehicle has no traction battery. Due to the different performance requirements between a hybrid and plug-in hybrid vehicle two different battery technologies were considered in the simulation to choose the optimal one for each hybrid vehicle configuration. For the hybrid FC vehicle architecture, the battery must provide at least $40 \mathrm{~kW}$ and thus, $\mathrm{LiFePO}_{4}$ was the chemistry used because of its high power performance with reduced battery size. On the contrary, the plug-in hybrid FC vehicle must fulfil not only power requirements, but mainly energy storage ones, to accumulate energy with the minor weight and volume. For these reason the chemistry in this case was LiNiCo which is more suited for power storage.

\subsubsection{FC System Efficiency}

Regarding motor and FC system, apart from power,
Table 3 Vehicles' power units specification.

\begin{tabular}{|c|c|c|c|}
\hline & $\begin{array}{l}U \\
0 \\
0 \\
0 \\
0\end{array}$ & 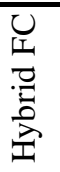 & 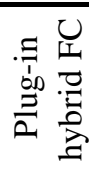 \\
\hline Motor Power (kW) & 70 & 70 & 70 \\
\hline Battery Power $(\mathrm{kW})$ & - & 40 & 108 \\
\hline FC Power $(\mathrm{kW})$ & 100 & 30 & 8 \\
\hline
\end{tabular}

Table 4 Accumulation [5] and traction systems' characteristics.

\begin{tabular}{|c|c|c|}
\hline & $\begin{array}{c}\text { Power } \\
\text { density } \\
(\mathrm{kW} / \mathrm{kg})\end{array}$ & $\begin{array}{c}\text { Energy } \\
\text { density } \\
(\mathrm{kWh} / \mathrm{kg})\end{array}$ \\
\hline \multicolumn{3}{|l|}{ Fuel cell system } \\
\hline Fuel cell & 0.65 & - \\
\hline Hydrogen tank & - & 1.8 \\
\hline \multicolumn{3}{|c|}{ Traction HV battery } \\
\hline LiNiCo chemistry (Hybrid FC) & 1.905 & 0.094 \\
\hline LiFePO4 chemistry (Plug-in H. FC) & 0.482 & 0.132 \\
\hline
\end{tabular}

other key point to be considered is the efficiency, which depends on the power load.

For simulation, the average motor efficiency was used as specified in Table 2. This assumption is acceptable because the three vehicles perform the same cycles, and, as the mechanical part is the same for all of them, the motor operative points are similar and an average efficiency can be assumed. However, the operative points of the FC of each vehicle are substantially different because of their different FC sizes and energy management strategies. Thus, special care must be taken to simulate the FC instantaneous behaviour.

Normally FC stacks are systems with efficiency up to $50-60 \%$ as shown hereinafter in Fig. 4. The FC efficiency curves were considered to be scalable to the FC size with a local maximum of $60 \%$ efficiency at $40 \%$ load point [3] as shown in Fig. 1.

\subsection{Mission Profiles}

Five cycles were selected to evaluate the vehicle consumption and range under a wide variety of situations. NEDC cycle was used to dimension the energy storage systems for each vehicle to reach the 


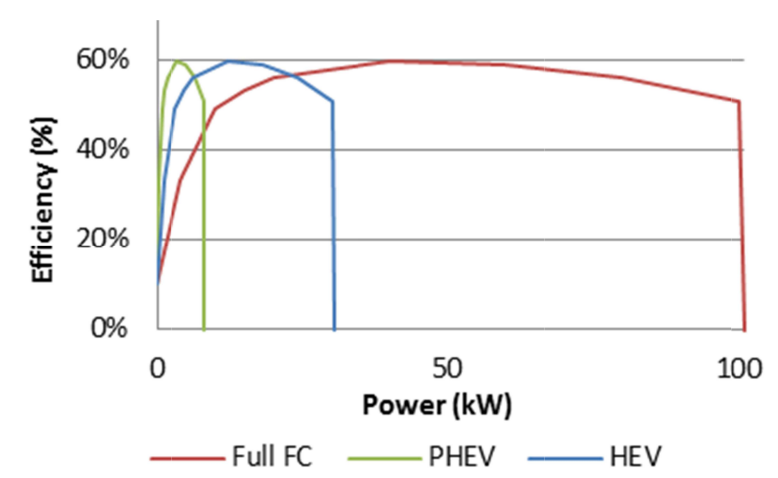

Fig. 4 FC efficiency curves for a $8 \mathrm{~kW}$ FC (green), a 30 kW FC (blue) and a $100 \mathrm{~kW} \mathrm{FC} \mathrm{(red)} \mathrm{[3]} \mathrm{.}$

target $500 \mathrm{~km}$ range, and the other cycles were used to develop the control strategy to provide good performance in different situations.

The NEDC [6] was selected to dimension the vehicle because is supposed to represent the typical usage of passenger car in Europe and is currently used in Europe to assess fuel economy.

The WLTP (worldwide harmonized light vehicles test procedures) cycle [7] and the Supplemental Federal Test Procedure cycle (US06) [8] were also selected as mission profiles to adapt the operating strategy to more dynamic and aggressive cycles.

Furthermore, another two customized profiles were defined. The first one is a simplified representation of highway driving at nearly constant speed of $120 \mathrm{~km} / \mathrm{h}$ as it would happen with cruise control with some decelerations to $100 \mathrm{~km} / \mathrm{h}$ as shown in Fig. 8. It is aimed to test the vehicle range performance under this situation that is very demanding for the vehicle with the low-powered FC.

The second customized cycle is meant to represent the real European urban and extra-urban driving profile based on a 3h-long measurement performed by IDIADA (Fig. 9).

As a summary, Table 5 compares some of the main characteristics of the five cycles to be simulated. It can be observed that steady 120 has the most demanding average speed while US06 combines the higher average acceleration with a high average speed. WLTP and real record cycles present similar acceleration levels to US06 but with significantly lower average speed, and thus they are less demanding. To end up with, NEDC requires very smooth accelerations and low average speed, being one of the less demanding cycles of the table.

\section{Concepts Development}

The three abovementioned vehicle architectures were studied in-depth during simulation with the purpose of optimizing the operating strategy to reach $500 \mathrm{~km}$ of range in NEDC with the minimum energy storage as possible. In this section, the three simulations are first explained in detail and at the end the results are summarized and discussed in Section 3.4 .

The models were developed in the 1D simulation software vemSim that runs in Matlab/Simulink environment, and the controller was implemented in Simulink. Figs. 1-3 show the block diagrams in vemSim.

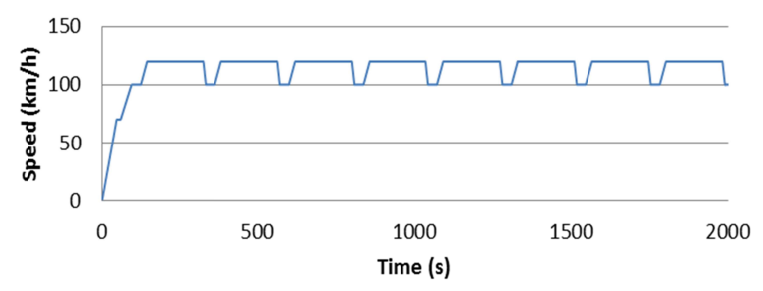

Fig. 8 Conceptual highway driving profile.

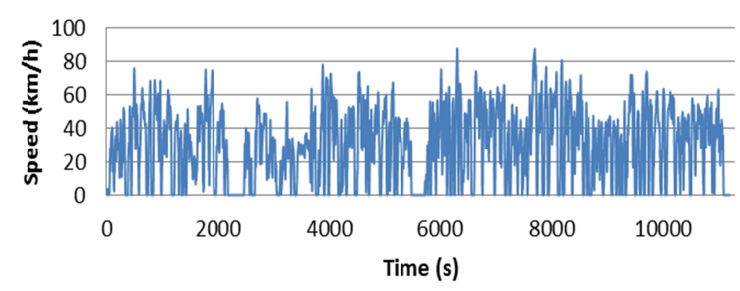

Fig. 9 Measured urban and extra-urban driving profile.

Table 5 Driving cycles main characteristics.

\begin{tabular}{|l|c|c|c|c|}
\cline { 2 - 5 } \multicolumn{1}{c|}{} & $\begin{array}{c}\text { V max } \\
(\mathrm{km} / \mathrm{h})\end{array}$ & $\begin{array}{c}\text { V avg } \\
(\mathrm{km} / \mathrm{h})\end{array}$ & $\begin{array}{c}\text { Time } \\
\text { stopped }\end{array}$ & $\begin{array}{c}\text { a avg } \\
(\mathrm{m} / \mathrm{s} 2)\end{array}$ \\
\hline NEDC & 120 & 34 & $23 \%$ & 0.26 \\
\hline WLTP & 131 & 47 & $12 \%$ & 0.45 \\
\hline US06 & 129 & 77 & $7 \%$ & 0.48 \\
\hline Steady 120 & 120 & 116 & $0 \%$ & 0.10 \\
\hline Real Record & 88 & 30 & $15 \%$ & 0.46 \\
\hline
\end{tabular}


For the development of the three concepts, an initial energy management strategy was defined. Then, the software performed iterations to obtain a battery and hydrogen storage that fitted with the $500 \mathrm{~km}$ NEDC range target [9]. It was an iterative process because the battery and Hydrogen tank sizes affected the vehicle weight which affects consumption and thus range. Afterwards, the performance on the different mission profiles was tested. The operating strategy was improved to permit a soft FC power profile operating close to the best efficiency point while maintaining an adequate SOC of the battery and a reasonable full electric range for the plug-in case. Then the energy storage size was modified in the cases that the new strategy affected the NEDC range and the mission profiles were tested again. Fig. 10 shows the flow diagram of the design process.

\subsection{Pure FC Vehicle}

\subsubsection{Starting Conditions}

The initial condition for the range simulation was vehicle stopped and $\mathrm{H}_{2}$ tank completely full.

3.1.2 Vehicle Development as per the Mission Profiles

Due to the lack of another traction source apart from a FC, the power distribution required by the NEDC cycle corresponds to the FC's power distribution as shown in the histograms in Fig. 16. This means that all the electric power is supplied to the traction system by the $\mathrm{FC}$ as shown in Fig. 10. Thus, the $\mathrm{H}_{2}$ tank itself has to store enough $\mathrm{H}_{2}$ to cover the target NEDC range.

It can be observed that the $\mathrm{FC}$ is continuously working in traction situation, and is off when the vehicle is decelerating or stopped. Then, the auxiliary accumulator that is charged during traction provides enough energy to supply the $400 \mathrm{~W}$ auxiliaries' consumption, and allows the FC to be switched off. This accumulator prevents the FC from working at 400 $\mathrm{W}$ and very low efficiency when no traction is required. Simulations showed that connecting the auxiliaries directly to the FC would increase the total $\mathrm{H}_{2}$ consumption by $9.5 \%$, which means $14.6 \mathrm{~kg}$ more of $\mathrm{H}_{2}$ tank. This accumulator is just used to supply energy to the auxiliaries and it is not suited for regenerative braking.

As per the power demand required for NEDC, it can be observed that the FC power profile is very variable (Fig. 11) and it operates at low load and low efficiency points. The maximum power provided by the $\mathrm{FC}$ is 40 $\mathrm{kW}$ which means that it reaches its maximum efficiency point just once in a complete cycle. According to that, the $\mathrm{H}_{2}$ tank is not only dimensioned to cover the cycle requirements, but also the $\mathrm{FC}$ efficiency reduction.

The detailed weight and energy consumption results obtained for the pure FC vehicle are presented in Section 3.4.

\subsection{Hybrid FC vehicle}

\subsubsection{Starting Conditions}

As the battery cannot be recharged to its maximum

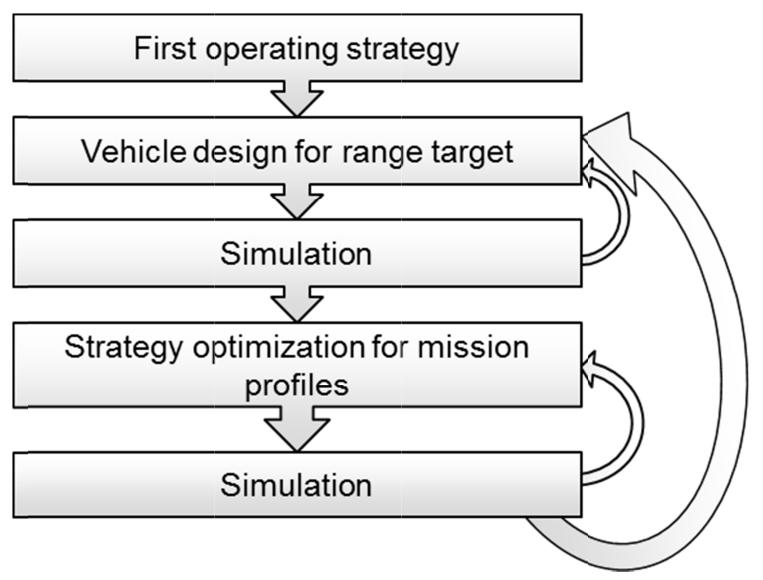

Fig. 10 Flow diagram of the design process.

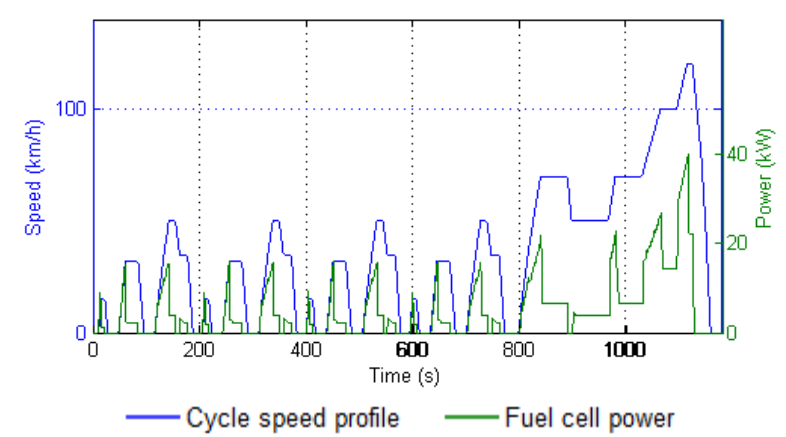

Fig. 11 Pure FC vehicle power profile on NEDC. 

Impact on Range, Weight and Energy Consumption

capacity, the initial SOC (state of charge) was for the range simulation was set following the European Regulation No. 101 [6] for hybrid electric vehicles not externally chargeable: before testing, a previous preconditioning test must be performed in which at least two consecutive complete driving cycles are carried out without soak. Independently of the initial battery SOC, at the end of driving a preconditioning cycle, the final SOC is within $60 \%-80 \%$. Therefore, the initial condition for the range simulation was vehicle stopped $\mathrm{H}_{2}$ tank completely full and traction battery at $70 \%$ of initial SOC.

3.2.2 Energy Management as per the Mission Profiles

The strategy followed is depicted in Table 6. Under this strategy, the FC of $30 \mathrm{~kW}$ will always operate at its maximum efficiency power or at higher loads in which the efficiency is also very favourable to maintain the battery SOC within $40 \%-80 \%$. This strategy was set to reach the minimum consumption on the five abovementioned cycles by iterating with different operating strategy charts.

The colour scales in Table 6 show the strategy to follow at each moment depending on the traction battery SOC and power demanded by the vehicle

Table 6 Hybrid FC consumption strategy.

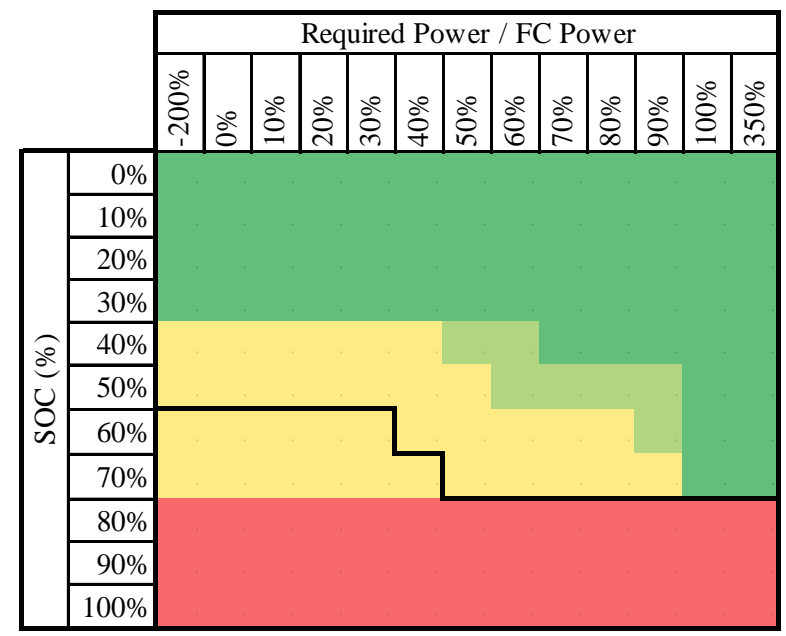

FC off

$\mathrm{FC}=\max$ eff

$\mathrm{FC}=$ cycle load compared with FC power. As the cycle power requirements are strongly variable, in order to maintain a soft operating strategy and not to demand abrupt load peaks to the FC, an exponential moving average of the cycle power demand with $4 \mathrm{~m}$ time constant was used instead of the instantaneous power demand. The exponential moving average weights the power loads exponentially giving more relevance to the last value. This method is fast to compute and does not require a record of all the previous power values. Furthermore, the variation of the $\mathrm{FC}$ power requirement coming from the strategy is limited to a maximum raise of $0.6 \mathrm{~kW} / \mathrm{s}$ when the power request increases and $-0.9 \mathrm{~kW} / \mathrm{s}$ when it decreases.

The black line marks in Table 6 represent the limit SOC at which the FC is switched on. The offset when switching the FC on and off at low power demand avoids the occurrence of fast and short on/off cycles that would imply many transitions from 0 to $12 \mathrm{~kW}$ load and low efficiency of the FC.

Thus, the strategy consists on trying to keep the SOC level within $40 \%$ and $80 \%$ and minimize hydrogen consumption by working as much time as possible at the maximum efficiency point of the FC. Therefore, the FC is aimed at being switched off and work at its maximum efficiency consecutively. However, although this behavior is the optimal in terms of $\mathrm{H}_{2}$ consumption, there must be some exceptions to maintain the battery SOC level. When the traction battery SOC is very low $(<40 \%)$ or the vehicle exponential moving average power demand is high compared to the FC power, the FC either follows the load demand point or works at its maximum power to feed the battery. Furthermore, when the instantaneous (not averaged) cycle power load exceeds $40 \mathrm{~kW}$, which is the maximum battery power, the FC must provide at least all the exceeding power to fulfil the requirement regardless of the strategy in Table 6. NEDC simulation description, as mentioned in Section 3.2.1, at the beginning of the NEDC cycle the traction battery is at $70 \%$ of SOC. Fig. 12 shows how the stored energy 

Impact on Range, Weight and Energy Consumption

evolves in time. When the most demanding part of the NEDC cycle is reached and thus the power requirement is higher, the $\mathrm{FC}$ is switched on at its maximum efficiency point. The NEDC power demand allows the FC to either work at its maximum efficiency point (12 $\mathrm{kW}$ ) or to be stopped. This FC on/off behaviour is repeated maintaining the SOC level within $50 \%$ and $80 \%$ until the $\mathrm{H}_{2}$ tank is empty. At that moment the battery provides all the power until it is completely depleted at $500 \mathrm{~km}$ range. More demanding cycles in which the FC needs to provide higher power levels are shown in Annex A.

Fig. 13 shows a representative NEDC cycle, in which it can be observed that the FC only operates at its maximum efficiency point $(12 \mathrm{~kW})$ in the most demanding part and that then it is switched off. The rest of the energy demanded by the cycle is provided by traction battery that absorbs all the power peaks and the regenerated energy. Thus, thanks to the traction battery and the energy management strategy, consumption is reduced in contrast to the pure FC vehicle because it

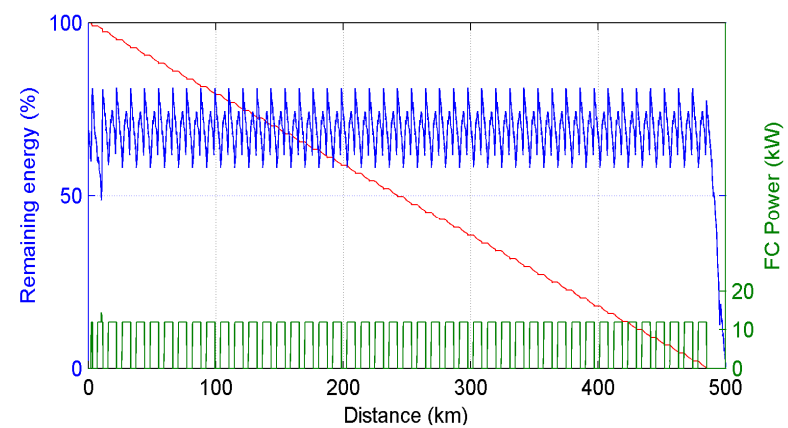

Fig. 12 Hybrid FC vehicle in NEDC: FC power and remaining $\mathrm{H}_{2}$ and $\mathrm{SOC}$ during a range simulation.

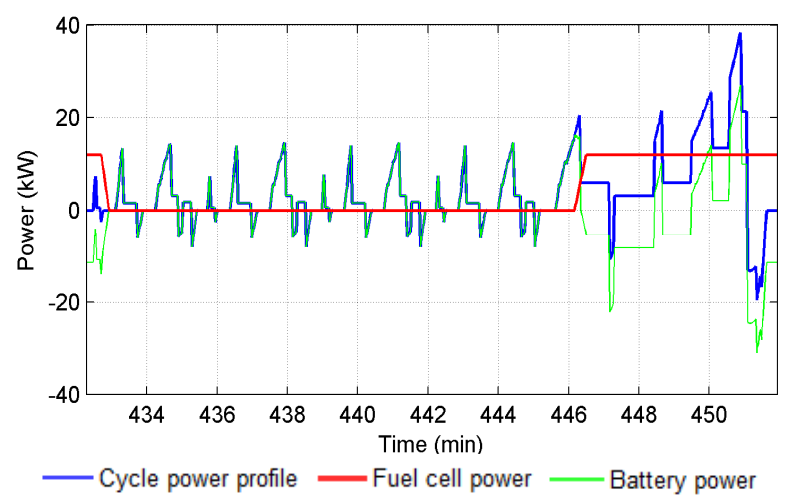

Fig. 13 Hybrid FC vehicle in NEDC: Power distribution in one cycle. allows regeneration and operation at the maximum efficiency points.

The detailed weight and energy consumption results obtained for the hybrid FC vehicle are presented in Section 3.4. The performance of this concept vehicle in other cycles can be observed in Annex A.

\subsection{Plug-in Hybrid FC Vehicle}

\subsubsection{Starting Conditions}

For this simulation, the initial condition is vehicle stopped, $\mathrm{H}_{2}$ tank full and battery charged at $100 \%$.

3.3.2 Energy Management as per the Mission Profiles

In this concept vehicle the traction battery admits external charge and the FC iss used as a range extender. The strategy followed (Table 7) is designed to reach a pure electric range of more than $80 \mathrm{~km}$ in NEDC cycle. This requirement is aimed at covering the daily mileage with electric energy only of $90 \%$ of the users according to Ref. [10], and thus, making use of the $\mathrm{H}_{2}$ just for long trips. Under this strategy first a battery depleting occurs to allow electric range and then the FC of $8 \mathrm{~kW}$ operates in high efficiency points to maintain the battery SOC within 30\%-50\%. This strategy was set to reach the minimum consumption and maximize the electric range for the five abovementioned cycles within the FC power limitations by iterating with

Table 7 Plug-in hybrid FC consumption strategy.

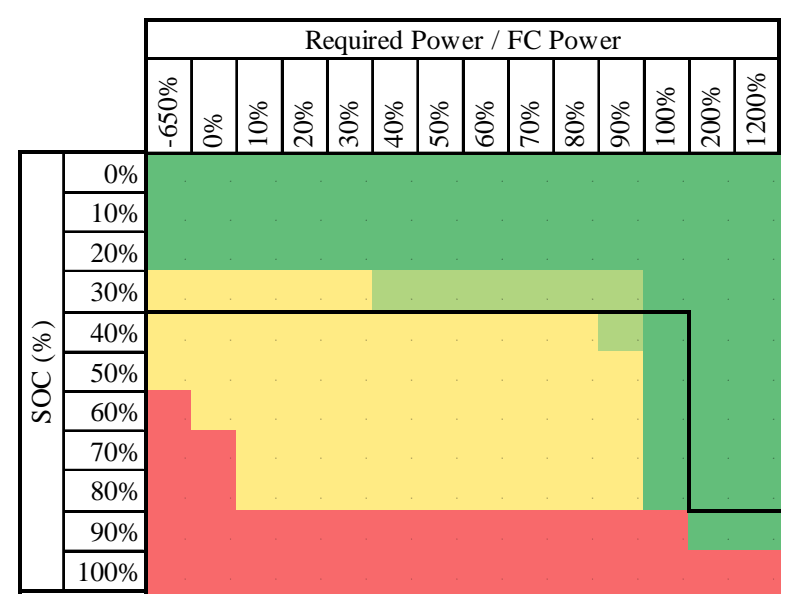

FC off $\mathrm{FC}=$ max eff.

$\mathrm{FC}=$ cycle load

$\mathrm{FC}=$ max power 
different operating strategy charts.

The colour scales and the black lines have the same function as in the hybrid strategy described in Section 3.2.2. The strategy to follow depends on the traction battery SOC and the exponential moving average power demanded by the vehicle compared to the FC power. The variation of the $\mathrm{FC}$ power requirement is also limited to $0.6 \mathrm{~kW} / \mathrm{s}$ and $-0.9 \mathrm{~kW} / \mathrm{s}$ to smooth the FC load profile.

The black line marks that represent the limit SOC at which the FC is switched on present a big offset with respect to the FC off SOC level for average loads lower than $16 \mathrm{~kW}$ to provide a high full electric range. However, when the demand is higher, the FC is switched on to its maximum power $(8 \mathrm{~kW})$ even though the SOC is high to avoid the battery discharging too fast. Even so, there are cases such as when driving in a highway at $120 \mathrm{~km} / \mathrm{h}$, in which the $\mathrm{FC}$ power is not enough to maintain the battery level and the vehicle is stopped ( $\mathrm{SOC}=0)$ when there is still remaining $\mathrm{H}_{2}$ in the tank (view Annex A). To avoid this phenomenon, a $15 \mathrm{~kW}$ FC or a speed limitation could be used as an alternative, and were proposed within the PUMA Mind project [2].

Under this strategy, for low- and medium-demanding cycles the FC will always operate at its maximum efficiency power or at higher loads in which the efficiency is also very favourable to maintain the battery SOC. As the FC maximum power is very low, it usually does not switch off after the full electric range, as it is demonstrated on Fig. 14 and on Figs. A.6 and A.9 of Annex A.

As mentioned in Section 3.3.1, in the beginning of NEDC cycle traction battery is at $100 \%$ of SOC and therefore the vehicle starts up in pure electric mode with the FC switched off. Fig. 14 shows how the energy stored evolves over time in the traction battery and the $\mathrm{H}_{2}$ tank. When the SOC decreases to $40 \%$ the FC starts working alternatively following the cycle load and at its maximum efficiency point $(3.2 \mathrm{~kW})$. With this strategy the pure electric range achieved is
$119.5 \mathrm{~km}$ and the SOC level is then maintained within $40 \%$ and $45 \%$. When all the hydrogen in the tank is consumed, the battery provides all the power until it is completely depleted for a range of $500 \mathrm{~km}$.

The NEDC range could have also been achieved by only operating the FC at its maximum efficiency point, but under this situation there would not be a full electric range which is the main advantage of plug-in vehicles.

As per the power demand required in NEDC, Fig. 15 shows a representative NEDC in which the FC operates only in its maximum efficiency point $(3.2 \mathrm{~kW})$ and partially at higher loads. The rest of the energy is provided by traction battery that absorbs all the power peaks and the regenerated energy. The consumption is reduced compared to the pure FC vehicle because traction battery is capable of regenerating and it allows the FC to work at high-efficiency operative points. However, it is less efficient than the hybrid vehicle because it works less time at its maximum efficiency point.

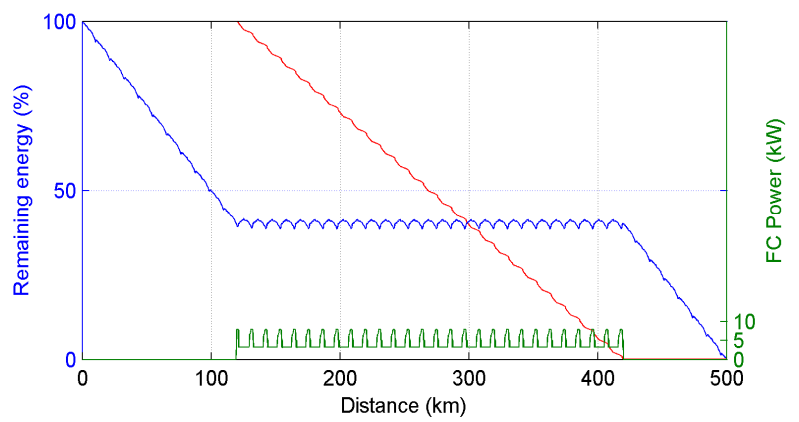

Fig. 14 Plug-in hybrid FC vehicle in NEDC: FC power and remaining $\mathrm{H}_{2}$ and $\mathrm{SOC}$ during a range simulation.

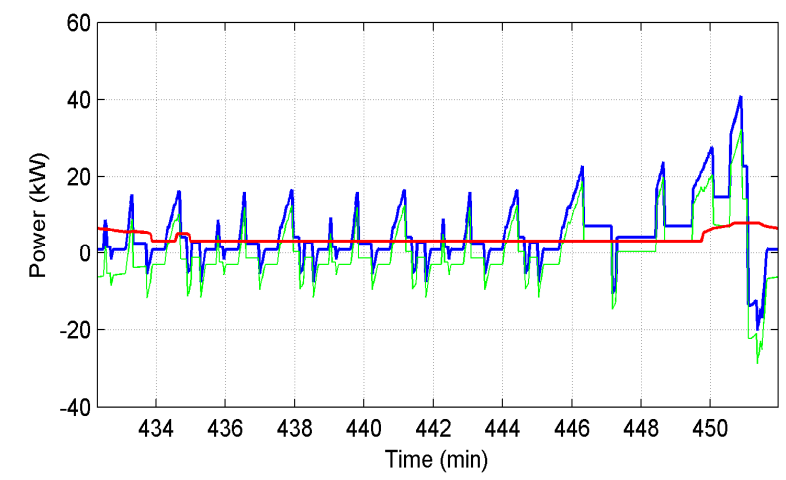

Fig. 15 Plug-in hybrid FC vehicle in NEDC: Power distribution in one cycle. 
The detailed weight and energy consumption results obtained for the hybrid FC vehicle are presented hereinafter. The performance of this concept vehicle in other cycles can be observed in Annex A.

\subsection{Concepts Comparison in NEDC}

The results in terms of weight, energy storage and consumption for the three concepts that are described in this section were obtained by iteration because a weight increase implies consumption and energy storage increase. For better understanding of the results, Fig. 16 shows the histogram of the power distribution demanded by the NEDC cycle and the ones followed by the three concepts. For better comparison, all graphs have the same axis limits and column width. The columns' size was chosen to be so small to be able to represent in detail the plug-in FC of only $8 \mathrm{~kW}$ power profile.

This graph summarizes a lot of information. The green columns represent either the cycle potential energy recovery or the recovered energy that comes back to the battery on each vehicle. It can be observed that the vehicles that include a battery are able to recover all this energy while the pure FC cannot and thus has higher electric consumption (Table 10). The blue columns represent either the time that the power requirement is zero for the cycle or the time that the FC is stopped. It can be observed that for the pure FC vehicle the FC is only off during decelerations or vehicle stopped while for the hybrid vehicle it is stopped almost $70 \%$ of the time. For the plug-in hybrid the total time that the FC is off taking into account the initial electric range and the final part is $40 \%$. The red columns represent either the required cycle power or the cycle profile followed by the FC. The pure FC vehicle follows the cycle power distribution and does not work at its maximum efficiency point of $40 \mathrm{~kW}$. On the other hand, the hybrid vehicle is optimized to work always at its maximum efficiency point of $12 \mathrm{~kW}$. To end up with, the plug-in vehicle works most of the time at its maximum efficiency load of $3.2 \mathrm{~kW}$ but has to reach higher loads to maintain the SOC level, and thus its average FC efficiency is lower than in the hybrid case. The results obtained by simulation that are described in the following paragraphs can be also derived from these power histograms.

The weight of the base vehicle, FC stack, batteries and hydrogen tank presented on Table 8 and Fig. 17 were calculated according to the densities that are specified in Section 2.2. It can be observed that the pure $\mathrm{FC}$ vehicle is the heavier because it requires a 100 $\mathrm{kW}$ FC and a big $\mathrm{H}_{2}$ tank due to the absence of regeneration and its reduced average efficiency. The plug-in case is also heavy compared to the hybrid FC due to the weight of the battery.
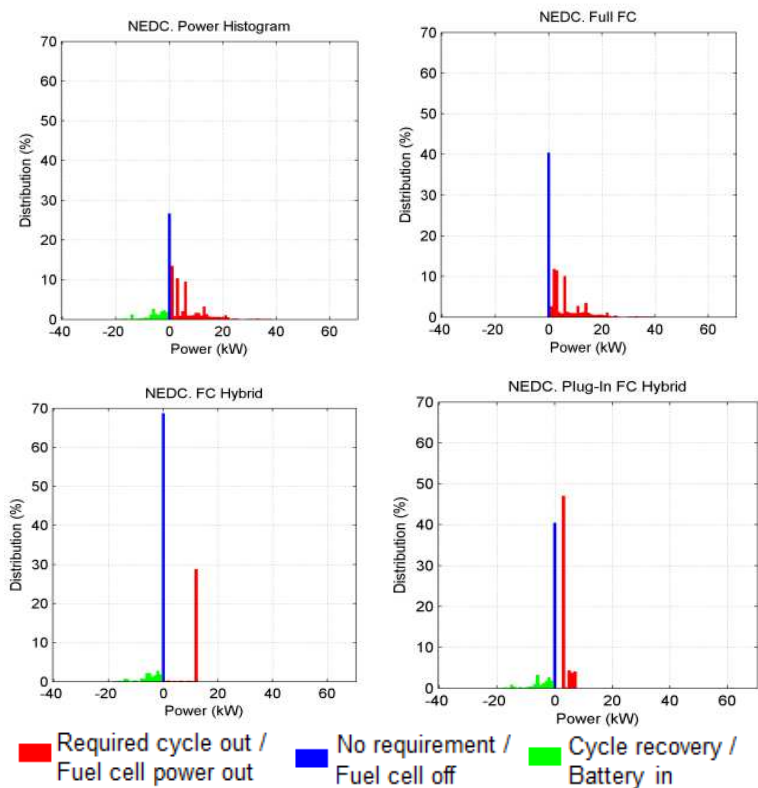

Fig. 16 Vehicle power distribution histogram for NEDC cycle: (a) cycle requirements; (b) pure FC vehicle; (c) hybrid FC vehicle; (d) plug-in hybrid FC vehicle.

Table 8 Resulting components' and total weight for the three concepts.

\begin{tabular}{|l|c|c|c|}
\cline { 2 - 4 } \multicolumn{1}{c|}{} & $\mathcal{U}$ & $U$ & U \\
\hline Base weight $(\mathrm{kg})$ & 1100 & 1100 & 1100 \\
\hline Fuel Cell $(\mathrm{kg})$ & 154 & 46 & 12 \\
\hline H2 tank $(\mathrm{kg})$ & 87 & 50 & 33 \\
\hline Battery $(\mathrm{kg})$ & - & 21 & 167 \\
\hline Total mass $(\mathrm{kg})$ & 1341 & 1217 & 1312 \\
\hline
\end{tabular}




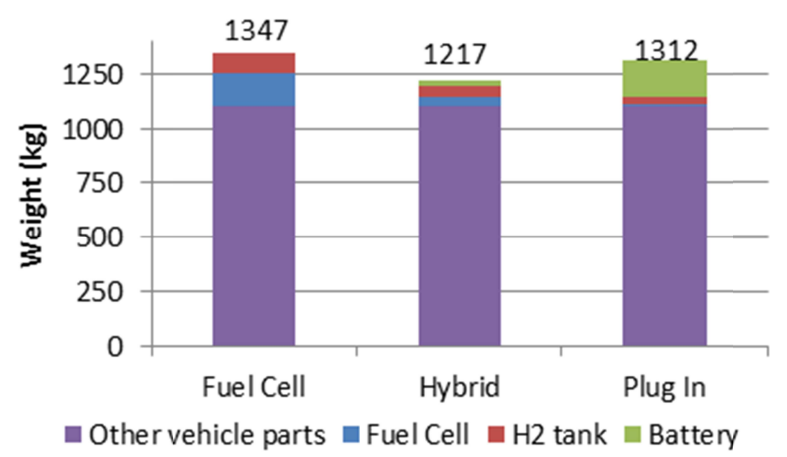

Fig. 17 Weight comparison for the three concepts.

Table 9 Stored energy in $\mathrm{H}_{2}$ tank and battery and equivalent $\mathrm{H}_{2}$ energy.

\begin{tabular}{|c|c|c|c|}
\hline & 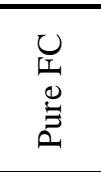 & 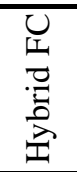 & 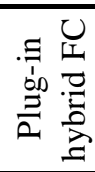 \\
\hline H2 tank energy ( $k W h)$ & 156.5 & 90.4 & 59.9 \\
\hline H2 elec. potential (kWh) & 89.2 & 51.5 & 34.1 \\
\hline Battery energy (kWh) & - & 2.0 & 22.0 \\
\hline
\end{tabular}

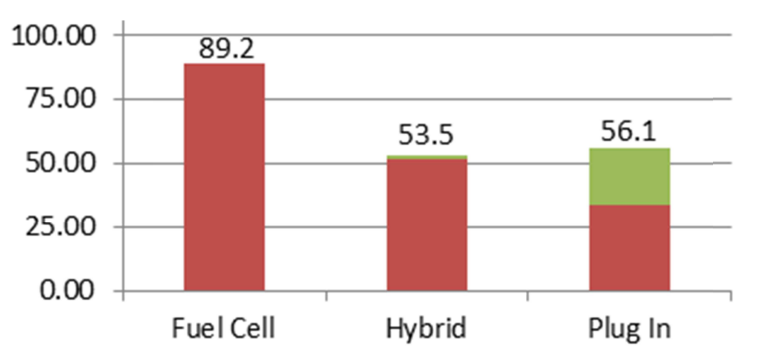

- $\mathrm{H} 2$ tank potential electric energy Battery energy

Fig. 18 Energy storage comparison for the three concepts.

Table 9 shows the energy stored in the $\mathrm{H}_{2}$ tank and the battery for each vehicle. In order to compare the energy stored in the same units, the $\mathrm{H}_{2}$ energy was translated into the equivalent electric energy that could be obtained the maximum FC efficiency of $60 \%$, which is the case presented in Fig. 18. It can be observed that even after translation the pure FC vehicle requires much more energy for the same range.

Finally, Table 10 summarizes the average FC efficiency, the electric consumption calculated in the motor, the $\mathrm{H}_{2}$ consumption and the equivalent $\mathrm{H}_{2}$ consumption taking into account the energy provided by the battery as generated by a FC at its maximum efficiency point. It states that the average efficiency of the FC is much lower in the pure FC case as abovementioned. Thus, the equivalent $\mathrm{H}_{2}$ consumption is also much higher.

\section{Concepts Evaluation}

Due to the scalability of the project, these three vehicles were designed to achieve high efficiency and range in other drive cycles. Thus, more simulations were performed with the weight and energy storage values that resulted in Section 3.4 for the WLTP, US06, steady 120 and real record cycle defined in Section 2.3. The detailed simulation results (power distribution, cycle profile, discharge profile, etc.) are represented in Fig. 19. The main results of these cycles are compared in the next paragraphs for the three vehicle configurations.

Fig. 19 shows the average efficiency of the FC during the cycles. It can be observed that for the pure FC vehicle the average efficiency is lower but for the cases of high-power-demanding cycles because it cannot follow an energy management strategy. Furthermore, the hybrid FC vehicle has higher average efficiency than the plug-in because its $30 \mathrm{~kW} \mathrm{FC}$ allows

Table 10 Average FC efficiency and specific consumption on NEDC cycle for the three concepts.

\begin{tabular}{|c|c|c|c|}
\hline & 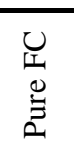 & 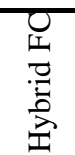 & 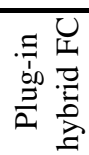 \\
\hline Avg. Fuel cell Eff. (\%) & $44 \%$ & $60 \%$ & $58 \%$ \\
\hline Comb. Electr. Cons. (Wh/km) & 148 & 105 & 110 \\
\hline $\mathrm{H} 2$ consumption $(\mathrm{Wh} / \mathrm{km})$ & 334 & 181 & 120 \\
\hline Equivalent $\mathrm{H} 2$ cons. (Wh/km) & 334 & 185 & 193 \\
\hline
\end{tabular}

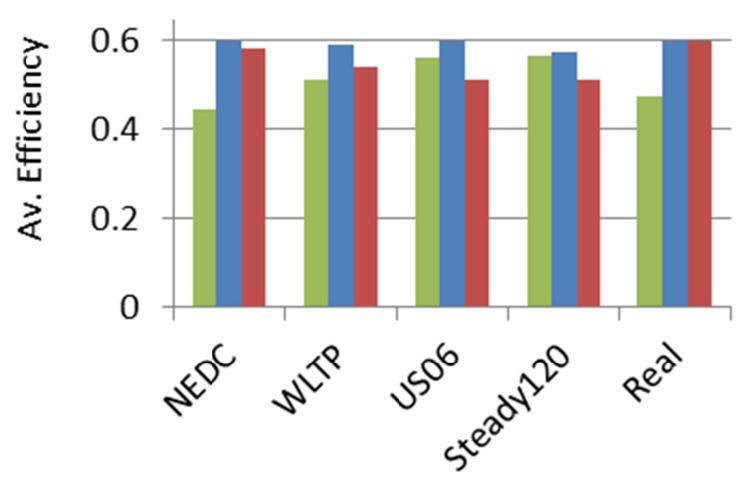

- Fuel Cell $\square$ Hybrid $\square$ Plug in

Fig. 19 FC average efficiency comparison. 
a greater part of the cycle to work at maximum efficiency.

Fig. 20 shows the $\mathrm{H}_{2}$ consumption increase for each case with respect to the optimal case of having regenerative brake and operation at the maximum efficiency point of the FC. It is evidenced that the hybrid concept operates very close to the optimal situation as well as the plug-in one while the pure FC undergoes an increase in consumption of up to $80 \%$.

Fig. 21 shows the electric consumption calculated in the motor, which is the result of the addition of the energy supplied by the battery and the FC, and thus, the average efficiency has no direct influence on this figure. It can be observed that the pure FC consumption is always higher due to the higher vehicle weight and the absence of regeneration, and that the difference is minimal for the steady 120 cycle that has few decelerations. In the same way, it can be observed that the plug-in vehicle always consumes more than the hybrid vehicle because it is heavier.

Regarding vehicle range, Fig. 22 shows that the pure FC vehicle maintains a similar range level for all the cycles because it has a big $\mathrm{H}_{2}$ storage and a higher average efficiency for the other cycles. On the other hand, the hybrid concept lowers the range for the more demanding cycles (WLTP, US06 and steady 120) because although it keeps working at maximum efficiency the power demand is higher. The plug-in hybrid presents a considerable full electric range for the urban and extra-urban cycles (119 km for NEDC, 102 $\mathrm{km}$ for WLTP, and $124 \mathrm{~km}$ for real record), overcoming the initial target of $80 \mathrm{~km}$ due to the big traction battery necessary to complement the small 8 kW FC.

On the other hand, under this vehicle configuration, the vehicle range at cycles US06 and steady 120 is diminished due not to lack of battery capacity but to the lack of FC power. In these cycles, there is remaining $\mathrm{H}_{2}$ in the tank when the vehicle is stopped that is not supplied because FC power is too low to maintain a constant SOC of the traction battery. This phenomenon

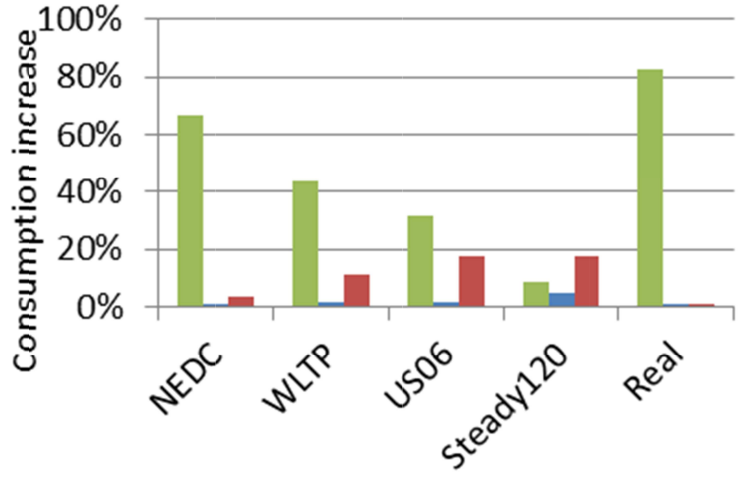

Fuel Cell $\square$ Hybrid $\square$ Plug in

Fig. $20 \mathrm{H}_{2}$ consumption increase compared to optimal FC efficiency and regenerative brake.

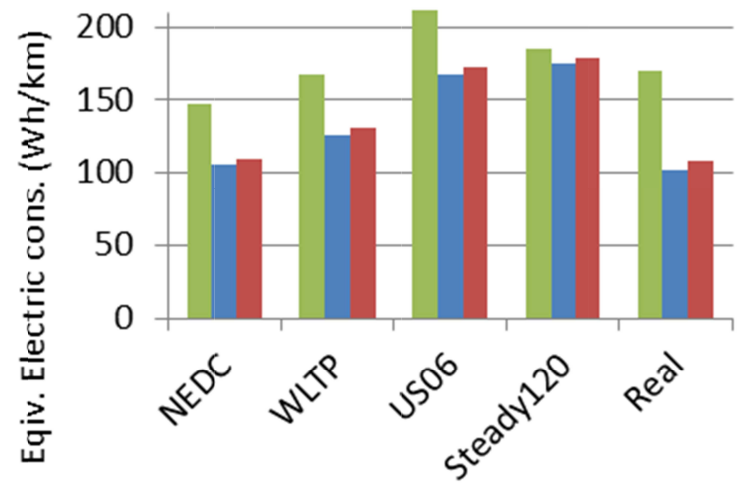

Fuel Cell Hybrid a Plug in

Fig. 21 Equivalent electric consumption.

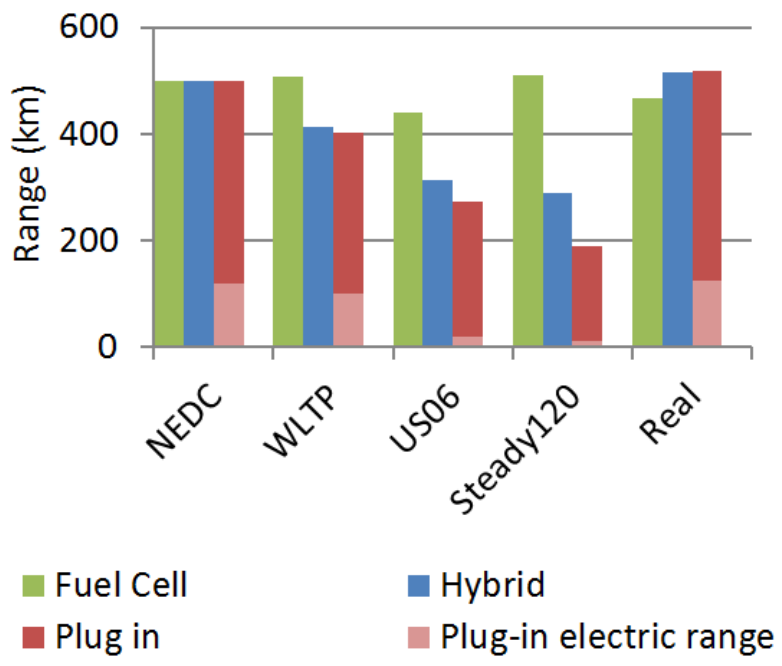

Fig. 22 Total range comparison.

can be observed in Figs. A.6 and A.9 of Annex A. As the FC is undersized for the US06 and steady 120 cycles, a powerful FC of $15 \mathrm{~kW}$ for the plug-in vehicle was also simulated by IDIADA in the PUMA Mind project [2] and proved to overcome this limitation, but 
at the end the $8 \mathrm{~kW}$ option was selected as established in the premises of the project.

\section{Conclusions}

Range anxiety is one of the most important drawbacks when buying an alternative powertrain electric vehicle. Therefore, in this study, a range of 500 $\mathrm{km}$ in the NEDC driving cycle was set as a target of three fuel cell-powered vehicles to reduce any inconvenience and deal with the introduction of new alternative power sources such as FCs.

Three concept vehicles where developed through simulation in vemSim software, namely a pure FC, a hybrid FC and a plug-in hybrid FC. Depending on the vehicle's architecture, relevant information in terms of energy consumption was obtained. The results of the simulation showed that the addition of a traction battery to hybridize the vehicle reduces the energy consumption because it allows regeneration and the implementation of energy management strategies to operate the FC at its more efficient loads.

The energy management strategy developed for the hybrid cases was implemented in Simulink within vemSim environment and was optimized through an iterative process. The strategies are described and their benefits are demonstrated through higher average operating efficiency of the FC for these two cases in comparison to the pure $\mathrm{FC}$ vehicle.

Finally, the resulting vehicle concepts were simulated in other driving situations with different demand levels to evaluate the overall powertrain behaviour. According to the initial premises that were aimed at a $\mathrm{C}$-segment vehicle, the results in terms of vehicle capabilities were reached successfully.

\section{References}

[1] Tazelaar, E., and Veenhuizen, B. HAN University of Applied Sciences, the Netherlands. Energy Management for Fuel Cell Hybrid Vehicles; On Road Evaluation.

[2] Puma Mind. http://www.pumamind.eu.

[3] Feroli, D. 2009. "Control and Design of PEM Fuel Cell-Based Systems.” Ph.D. thesis, Universitat Politècnica de Catalunya.

[4] UN/ECE Regulation No. 1222/2009.

[5] Dávila, A., Romero, E., Roche, M., Mammetti, M., Gutierrez, J., and Lesemann, M. 2014. "The ELVA Project's EV Design Support Tool." Presented at SAE 2014 World Congress and Exhibition, USA.

[6] UN/ECE, Regulation No. 101, $\mathrm{CO}_{2}$ Emission/Fuel Consumption.

[7] UN/ECE, Informal document No.WLTP-01-03.

[8] 40 CFR 86.159-08, Exhaust Emission Test Procedures for US06 Emissions.

[9] Roche, M., and Mammetti, M. 2015. "An Innovative Vehicle Behaviour Modelling Methodology for Model-Based Development." Presented at SAE 2015 World Congress and Exhibition, USA.

[10] Wu, Q., Nielsen, A. H., Østergaard, J., Cha, S. T., Marra, F., Chen, Y., and Træholt, C. 2010. "Driving Pattern Analysis for Electric Vehicle (EV) Grid Integration Study." Presented at 2010 IEEE PES Innovative Smart Grid Technologies Conference Europe (ISGT Europe), Gothenberg, Sweden.

\section{Annex A-Performances in Other Cycles}

\section{A.1 WLTP}
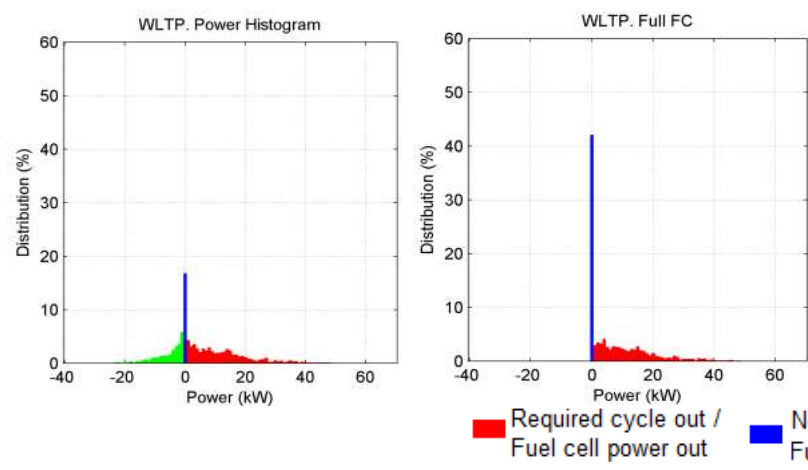

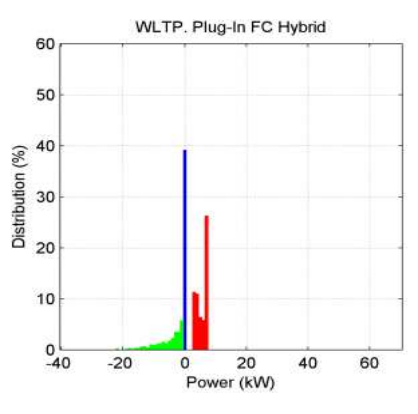

No requirement / Cycle recovery /

Fuel cell off $\quad$ Battery in

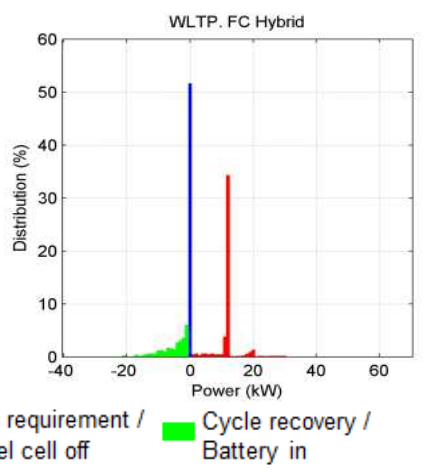

Fig. A.1 Vehicle power distribution histogram for WLTP: (a) cycle requirements; (b) pure FC vehicle; (c) hybrid FC vehicle; (d) plug-in hybrid FC vehicle. 

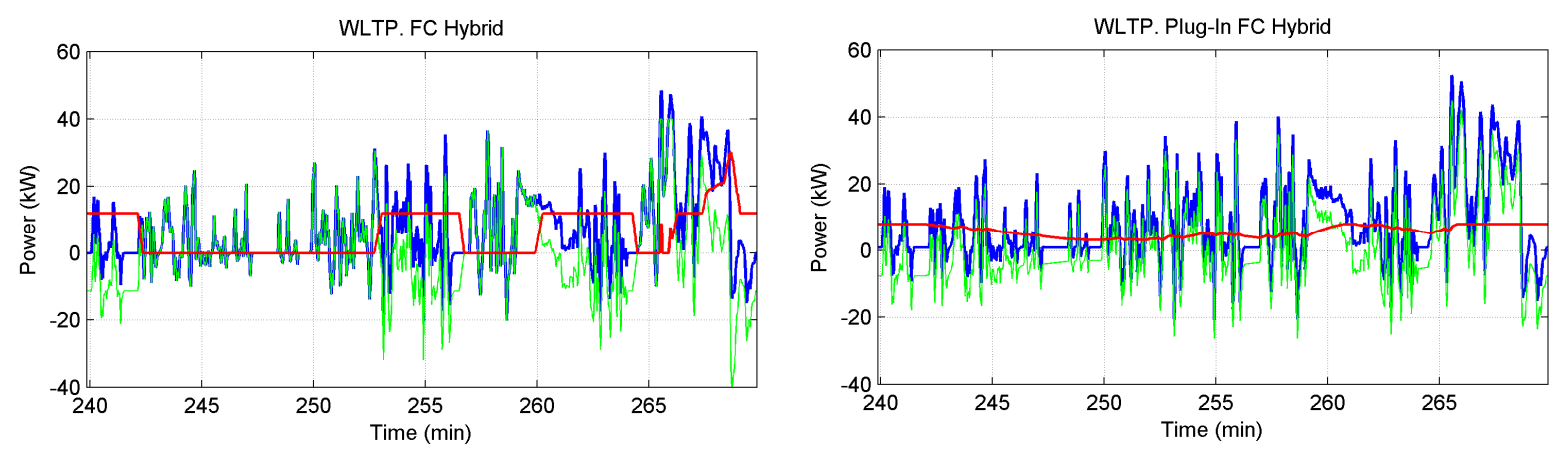

- Battery SOC — Remaining Hydrogen — Fuel cell power

Fig. A.2 Power distribution in one WLTP: (a) hybrid FC vehicle; (b) plug-in hybrid FC vehicle.
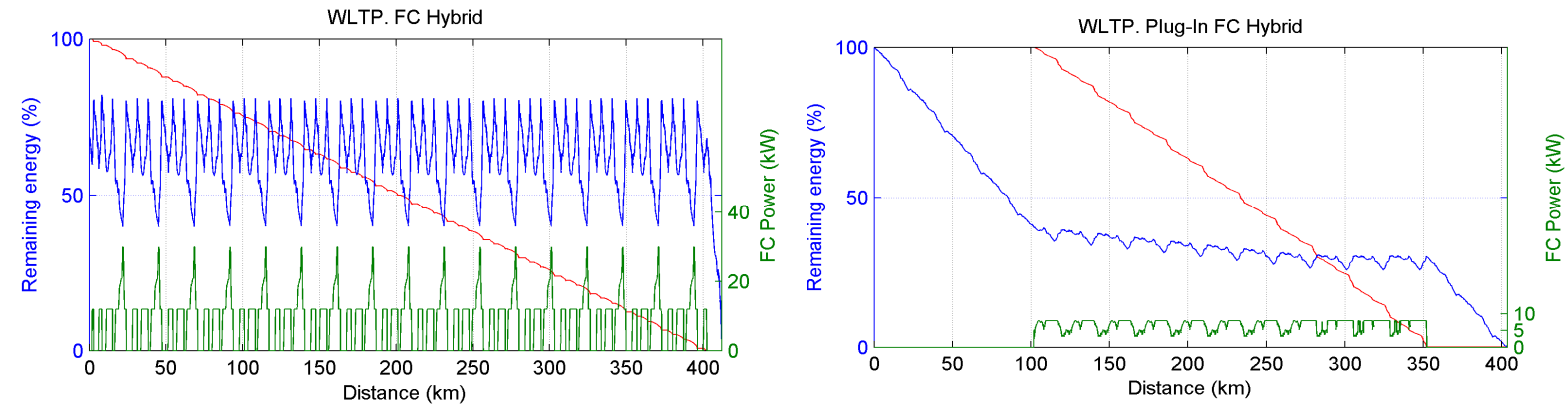

—Battery SOC — Remaining Hydrogen — Fuel cell power

Fig. A.3 FC power and remaining $\mathrm{H}_{2}$ and SOC during a WLTP range simulation: (a) hybrid FC vehicle; (b) plug-in hybrid FC vehicle.

\section{A.2 US06}
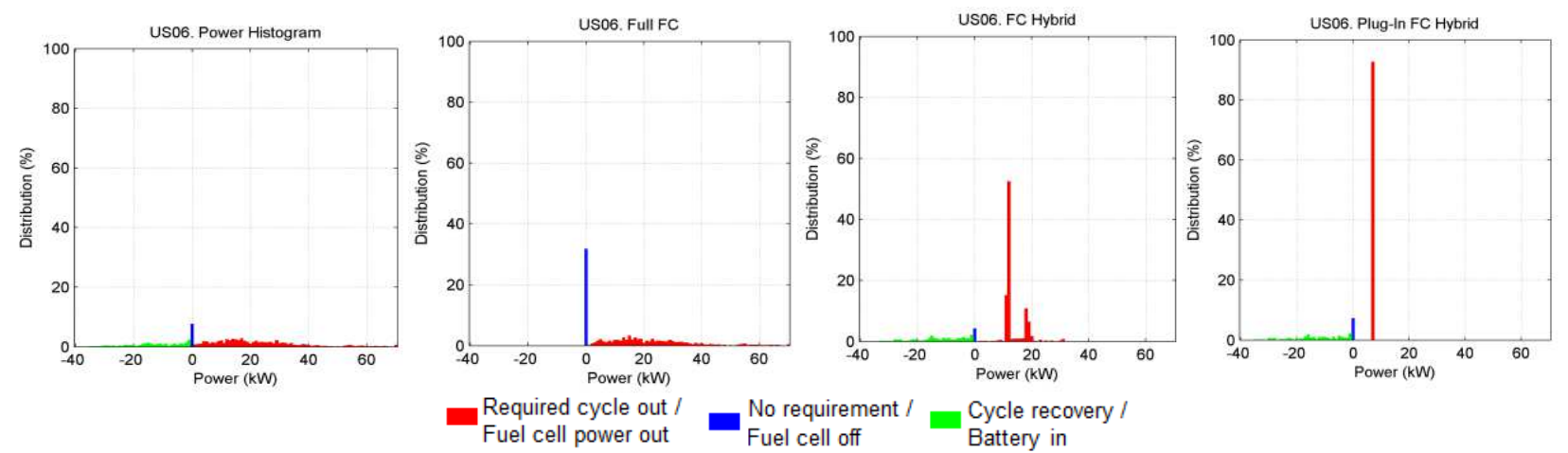

Fig. A.4 Vehicle power distribution histogram for US06 cycle: (a) cycle requirements; (b) pure FC vehicle; (c) hybrid FC vehicle; (d) plug-in hybrid FC vehicle.
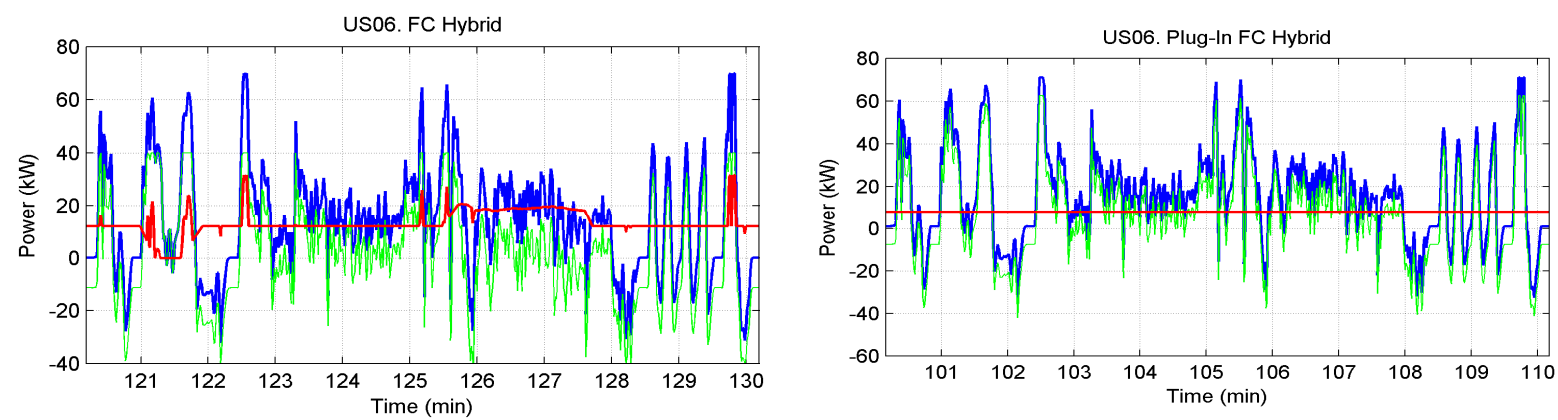

-Cycle power profile _-Fuel cell power —-Battery power

Fig. A.5 Power distribution in one US06: (a) hybrid FC vehicle; (b) plug-in hybrid FC vehicle. 

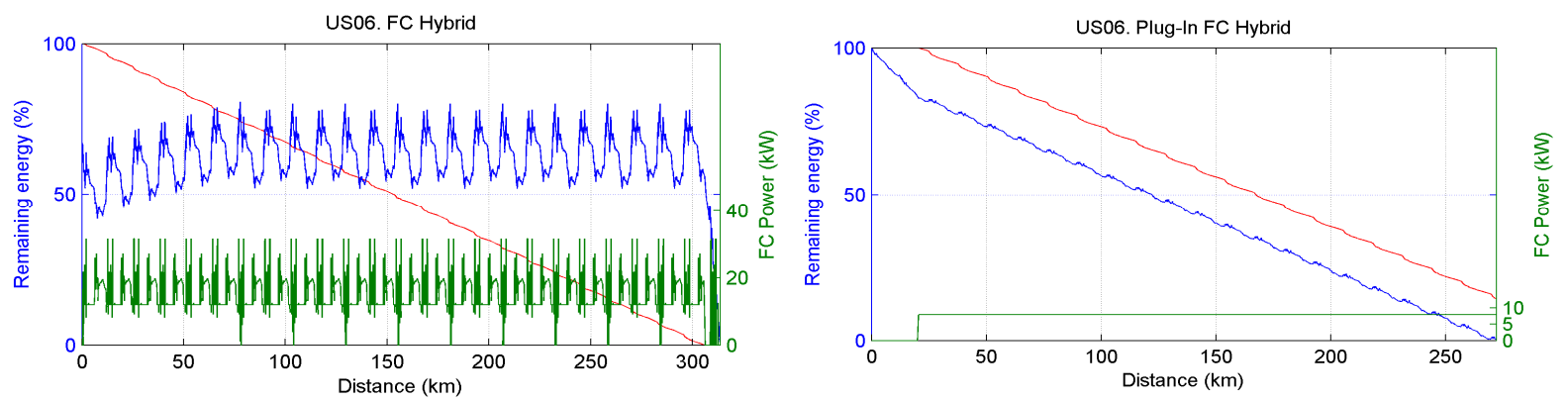

—Battery SOC — Remaining Hydrogen — Fuel cell power

Fig. A.6 FC power and remaining $\mathrm{H}_{2}$ and SOC during a US06 range simulation: (a) hybrid FC vehicle; (b) plug-in hybrid FC vehicle.

\section{A.3 Steady 120}
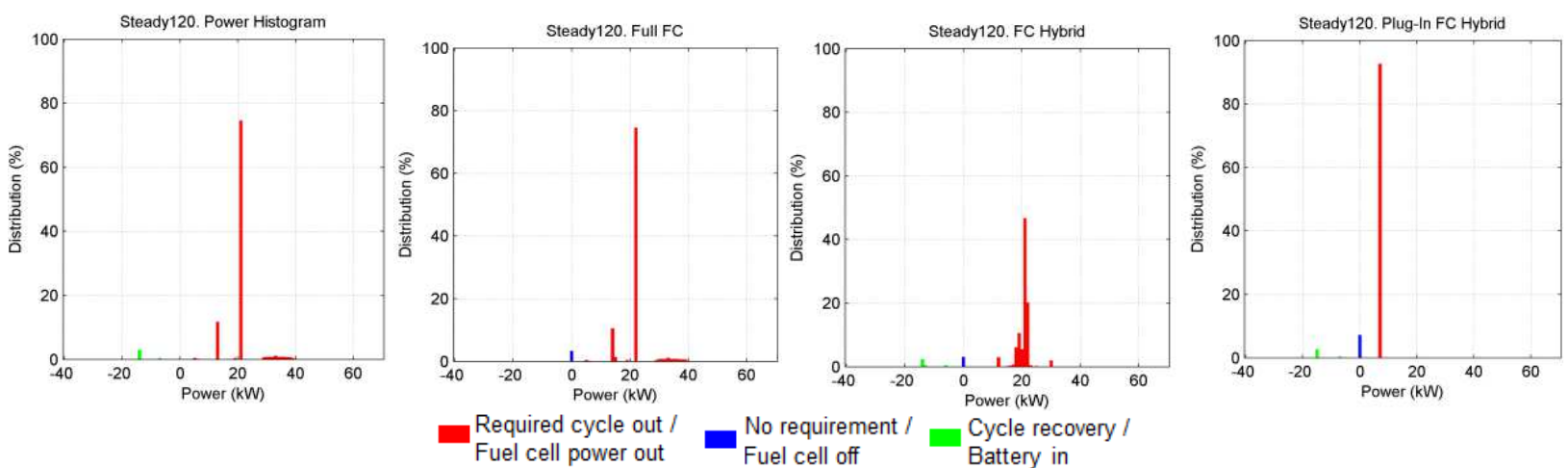

Fig. A.7 Vehicle power distribution histogram for steady 120 cycle: (a) cycle requirements; (b) pure FC vehicle; (c) hybrid FC vehicle; (d) plug-in hybrid FC vehicle.
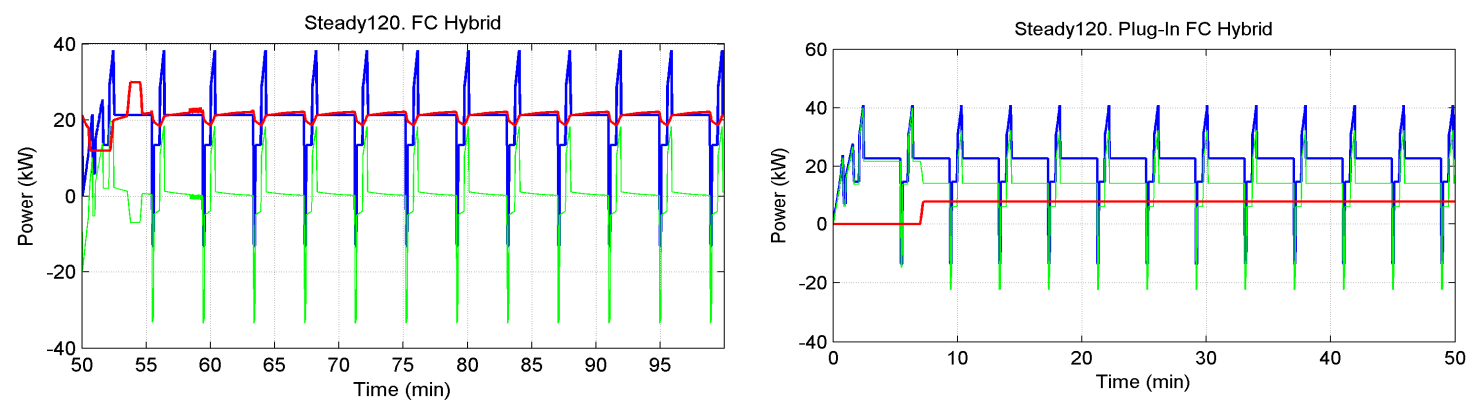

—Cycle power profile — Fuel cell power —-Battery power — Battery SOC — Remaining Hydrogen — Fuel cell power

Fig. A.8 Power distribution in steady 120: (a) hybrid FC vehicle; (b) plug-in hybrid FC vehicle.
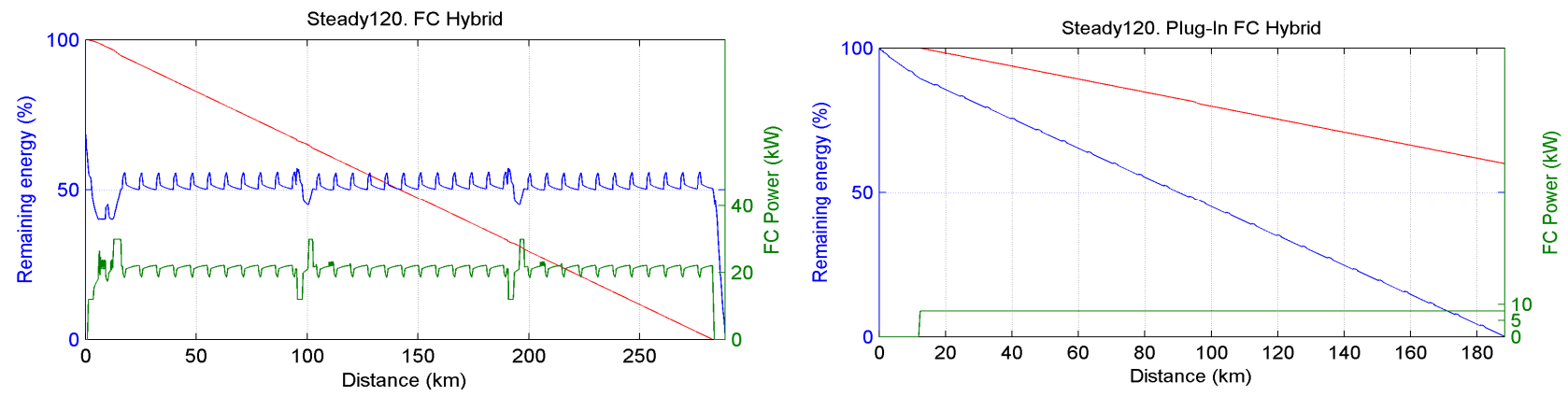

- Battery SOC — Remaining Hydrogen — Fuel cell power

Fig. A.9 FC power and remaining $\mathrm{H}_{2}$ and SOC during a steady 120 range simulation: (a) hybrid FC vehicle; (b) plug-in hybrid FC vehicle. 


\section{A.4 Real Record}
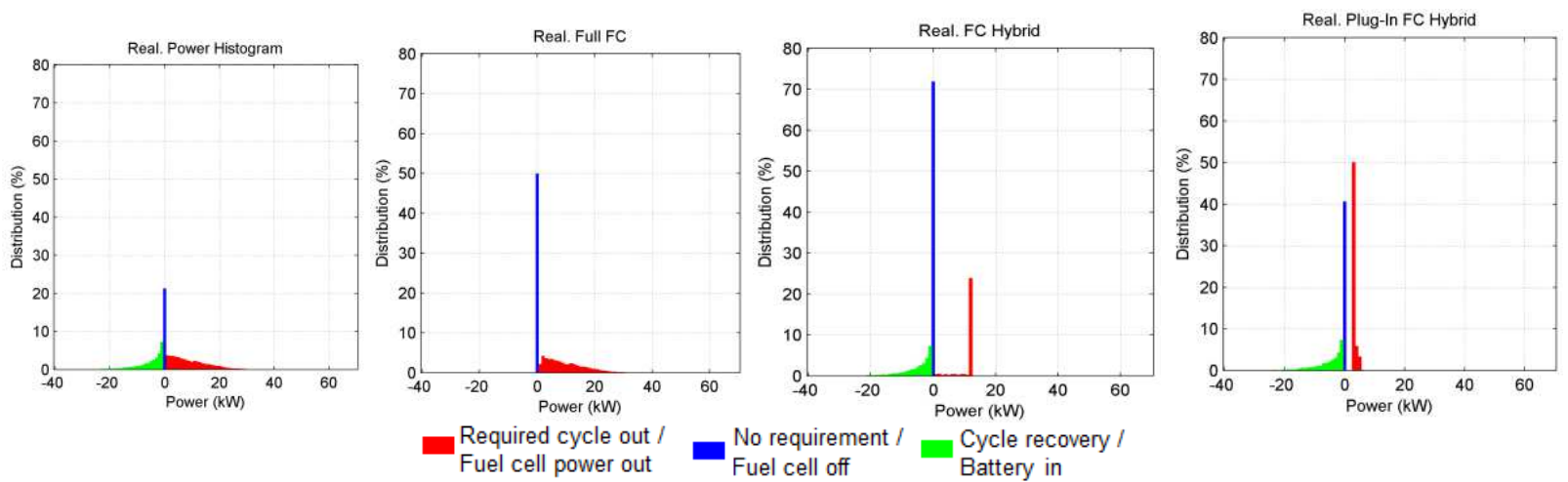

Fig. A.10 Vehicle power distribution histogram for real record cycle: (a) cycle requirements; (b) pure FC vehicle; (c) hybrid FC vehicle; (d) plug-in hybrid FC vehicle.
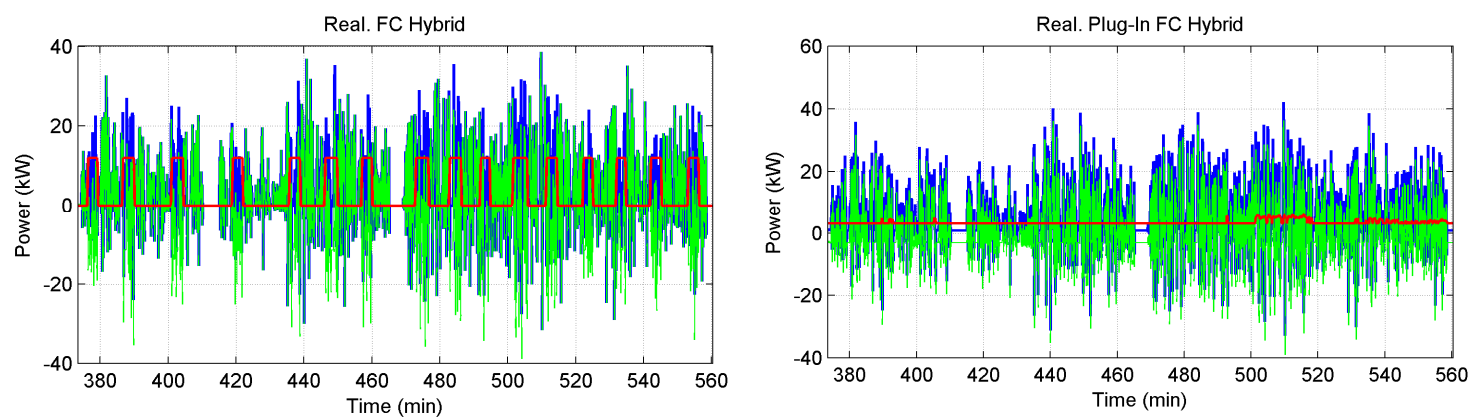

— Cycle power profile _-Fuel cell power — Battery power

Fig. A.11 Power distribution in real record: (a) hybrid FC vehicle; (b) plug-in hybrid FC vehicle.
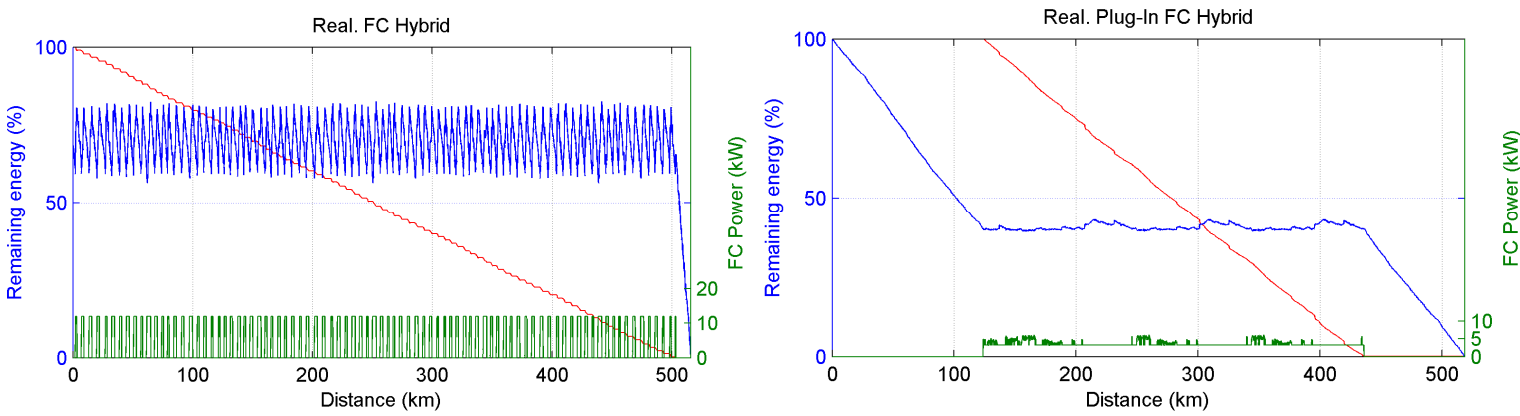

—Battery SOC — Remaining Hydrogen —-Fuel cell power

Fig. A.12 FC power and remaining $\mathrm{H}_{2}$ and SOC during a real record range simulation: (a) hybrid FC vehicle; (b) plug-in hybrid FC vehicle. 